\title{
The brain decade in debate: IV. Chronobiology
}

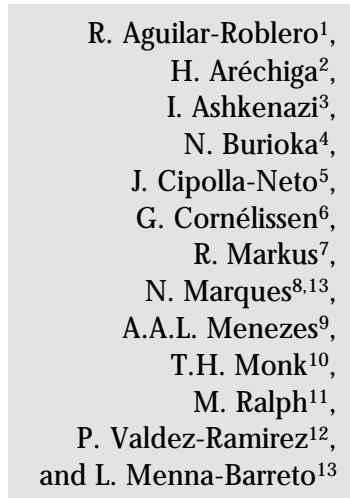

\section{Correspondence}

L. Menna-Barreto

Grupo Multidisciplinar de

Desenvolvimento e Ritmos Biológicos

Departamento de Fisiologia e

Biofísica, ICB, USP

Av. Prof. Lineu Prestes, 1524

05508-900 São Paulo, SP

Brasil

E-mail: menna@fisio.icb.usp.br

Publication supported by FAPESP

The names of the authors are presented in alphabetic order, except for the last who was the symposium organizer.

Received October 31, 2000 Accepted May 2, 2001

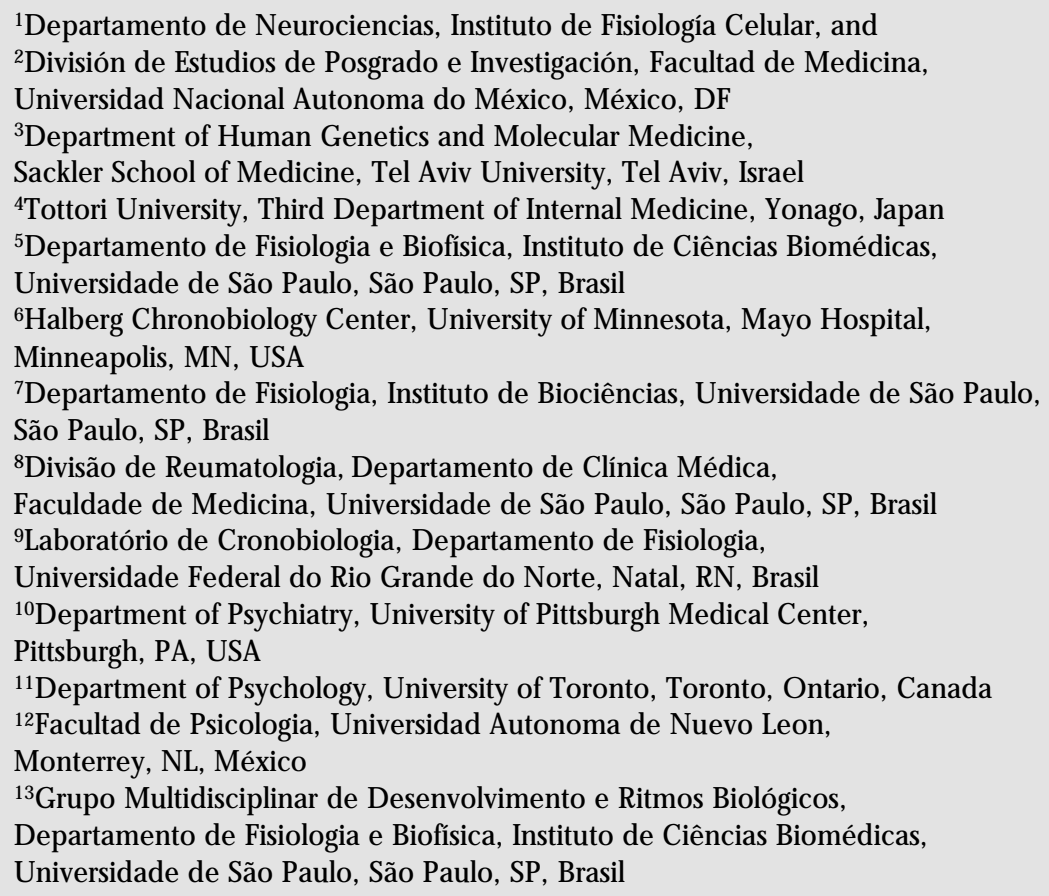

1Departamento de Neurociencias, Instituto de Fisiología Celular, and 2División de Estudios de Posgrado e Investigación, Facultad de M edicina, Universidad Nacional Autonoma do México, México, DF ${ }^{3}$ Department of Human Genetics and Molecular Medicine, Sackler School of M edicine, Tel Aviv U niversity, Tel Aviv, Israel ${ }^{4}$ Tottori U niversity, Third Department of Internal M edicine, Yonago, Japan ${ }^{5}$ Departamento de Fisiologia e Biofísica, Instituto de Ciências Biomédicas, Universidade de São Paulo, São Paulo, SP, Brasil ${ }^{6} \mathrm{H}$ alberg Chronobiology Center, U niversity of M innesota, Mayo Hospital, Minneapolis, MN, USA ${ }^{7}$ Departamento de Fisiologia, Instituto de Biociências, U niversidade de São Paulo, São Paulo, SP, Brasil ${ }^{8}$ Divisão de Reumatologia, Departamento de Clínica M édica, Faculdade de Medicina, U niversidade de São Paulo, São Paulo, SP, Brasil ${ }^{9}$ Laboratório de Cronobiologia, Departamento de Fisiologia, Universidade Federal do Rio Grande do Norte, Natal, RN, Brasil ${ }^{10}$ D epartment of Psychiatry, University of Pittsburgh M edical Center, Pittsburgh, PA, USA ${ }^{11}$ D epartment of Psychology, U niversity of Toronto, Toronto, O ntario, Canada ${ }^{12}$ Facultad de Psicologia, Universidad Autonoma de Nuevo Leon, Monterrey, NL, M éxico ${ }^{13}$ Grupo Multidisciplinar de Desenvolvimento e Ritmos Biológicos, Departamento de Fisiologia e Biofísica, Instituto de Ciências Biomédicas, Universidade de São Paulo, São Paulo, SP, Brasil

\section{Abstract}

The present article is the adapted version of an electronic symposium organized by the Brazilian Society of Neuroscience and Behavior (SBNeC) which took place on June 14, 2000. The text is divided into three sections: I. The main issues, II. Chronodrugs, and III. Methods. The first section is dedicated to the perspectives of chronobiology for the next decade, with opinions about the trends of future research being emitted and discussed. The second section deals mostly with drugs acting or potentially acting on the organism's timing systems. In the third section there are considerations about relevant methodological issues concerning data analysis.

\section{Introduction}

Although almost three centuries old, the idea of a timing system operating within living beings has come to maturity in the middle of the twentieth century, both on the basis of growing empirical evidence and dedicated effort of the pioneer scientists. Chrono-

\section{Key words}

- Chronobiology

- Biological rhythms

- Biological clocks

- Circadian and

ultradian rhythms

- Methodology biology may be defined today as a multidisciplinary effort to understand the temporal dimension of life, being mostly recognized by the study of the puzzling phenomena known as biological rhythms. Among these, circadian rhythms and the endogenous mechanisms that generate sustained oscillations in all levels of biological systems have 
drawn the attention of the scientific community. The purpose of this chat is to offer a picture of today's chronobiology as seen by some leading scientists in the field. The Brazilian Society of Neuroscience and Behavior ( $\mathrm{SBNeC})$ has asked me to chair this exchange of ideas which I hope will foster the development of chronobiology as well as help scientists from other areas see their biological phenomena under what may be called a "temporal light". I wish to express my gratitude to the $\mathrm{SBNeC}$ and to the Brazilian Journal of Medical and Biological Research for this opportunity to discuss our field of interest.

\section{The main issues}

Luiz Menna-Barreto: Welcome all to our Chrono-Chat. I would like to start by asking a general question: What are the main questions in the area of chronobiology that will be formulated and eventually answered in the next decade?

Israel Ashkenazi: One of the hottest issues today in the discipline of chronobiology relates to the genetic basis of biological clocks (rhythms). Most of the recent studies in this field including molecular genetics studies focused on the duration of the rhythm (the period) adhered to the conceived (dogmatic) concept of the circadian (or $24 \mathrm{~h}$ ) rhythm and thus concluded that the input of the basic (primary) gene yields a circadian (or $24 \mathrm{~h}$ ) output rhythm. I am slightly troubled by this conclusion. Let us define "period" as a trait. It is known that in most cases the intensity of a "trait" reflects the accumulated inputs of the two (or more) alleles (genes) related to this "trait". Viewing the data of King and Takahashi (1) with regard to the length of the activity period of his wild type, heterozygous and homozygous mutants (each genotype has a period length output differing from the other) leads to the conclusion that the primary gene of the "activity period" trait issues an input of 12-h length. If my argu- ment is correct, then the basic genes of biological clocks code for a $12-\mathrm{h}$ and not a $24-\mathrm{h}$ period length.

Hugo Aréchiga: As to the question posed by Menna-Barreto, it is my impression that in the next decade, the task of neurobiologists in disclosing the organization of circadian systems will proceed along the fundamental lines it has followed so far (2). a) Identifying the molecular clockwork, which is already an area of growing complexity. The basic molecular components will be characterized and definite progress will be made on their interactions to generate rhythmicity $(1,3)$. One area in particular need of progress is the characterization of the transcription factors conveying the circadian signals to downstream genes controlling overt rhythmicities. b) At the cellular level, the situation is similar, the characterization of circadian pacemakers will proceed together with the study of the cellular interactions in the ensembles generating the integrated circadian signals (4). c) At the integrative level, we still have much to learn about the interactions responsible for organizing entrainment and internal synchronization. Some interesting phylogenetic differences are being disclosed, suggesting that the generation of circadian rhythmicity is more centralized in mammals than in invertebrates (5-7). To close the gap from the molecular level to organ and individual levels of the expression of rhythmicity will be a formidable task for the near future (8), and finally, d) the implications of circadian rhythmicity in the larger scope of biology and medicine should be made stronger and clearer. I have the impression that we are not providing a persuasive chronobiological agenda for the medical community. In connection with Prof. Ashkenazi's question on the emergence of circadian rhythmicity from the interaction of ultradian pacemakers, this is a long-standing issue in chronophysiology. It has been debated for intact organisms, single cells and, more recently, at the molecular level. The existence 
of ultradian domains in rhythmicity is beyond question. A particularly conspicuous one is the tidal rhythm, with a periodicity near $12 \mathrm{~h}$, entrainable by pressure pulses (9). Also, in immature animals, before the circadian rhythm is fully integrated, ultradian frequencies are dominant, and a similar situation occurs when the circadian component is abolished in mature organisms, particularly after free-running under constant conditions; then, ultradian components become prevalent. Several theoretical models assume circadian rhythmicity as an emergent property of systems of ultradian pacemakers. However, there is growing evidence of the existence of a basic endogenous rhythmicity with a period close to $24 \mathrm{~h}$. Phase-response curves show a range of entrainability around the circadian frequency. The molecular loops generating circadian rhythmicity revolve around that period, both in mammals $(2,10)$ and in invertebrates (11). Actually, the same physiological function may be modulated by ultradian, circadian and infradian rhythmicities, even in single cells (12).

Naoto Burioka: I think that the nonlinear analysis of biological signals will become more important in the next decade, because chaotic properties are found in the signals from respiration, heart beat and electroencephalogram. The clock gene will be also very important.

Raul Aguilar-Roblero: In mammals, among the issues for the next decade are the functional and anatomical identification of other clocks besides the central nervous system (CNS), and how these clocks communicate among each other and with the rest of the organism. In humans, how about understanding the impact of internal synchronization on the mood and sense of well being?

Timothy Monk: I think we shall see huge advances in our understanding of the basic mechanisms of the circadian processes which may or may not lead to actual advances in people's everyday lives. I suppose the key to the real world impact of circadian advances in understanding will rest to a large extent upon their impact on our ability to manage sleep and wakefulness. If we can do this effectively (as is beginning to appear possible) then quite major effects on people's lives might occur. Thus, for example, if our understanding of the processes involved allows us to limit sleep to one or two hours per day without adverse symptoms, then we might see some quite dramatic life changes! I was thinking of our ability to attenuate the adverse symptoms of sleep loss seen, for example, at a very initial level with the use of Modafinil. This is just the beginning, but more sophisticated compounds might come along which can allow us to design our own sleep/wake patterns. We must keep in mind that sleep is important for many different mechanisms, and I do not think we will (or should) ever eliminate the need for sleep. The question is: can we get by with very little sleep (e.g., 2 h per day) if we can "fix" the adverse consequences that normally result?

Martin Ralph: Here are a few of my thoughts: 1) There will be a major thrust to identify genes of all sorts that have anything to do with circadian rhythms. The proliferation of identified genes will match that which occurred following the identification of the first cell cycle genes. 2) There will be an effort to relate circadian rhythms to human experience. The more we know about genetics, it seems, the more interested the general public becomes. 3) There will be a renewed effort to relate rhythmicity to other aspects of behavior. 4) There will be an effort to identify new and interesting models of circadian systems.

José Cipolla: I would dare to say that the most challenging issue to be faced will be the issue of the physiological (and behavioral) regulation of the circadian timing system with emphasis on the "hands" and not on the mechanism itself of the clock.

Nelson Marques: The integration of ideas may be the solution for the future, putting together physiological and behavioral ques- 
tions rather than only the genetic and molecular issues.

Germaine Cornélissen: One of the problems faced today is the high cost of health care. The impact of chronobiology can be enormous by permitting us to enter inside the physiological range where early alterations can be detected in terms of changes in rhythm parameters. It may thus be possible to diagnose pre-disease, before symptoms become overt and before there is target organ damage $(13,14)$. One case in point is the field of chronocardiology. Before there is an overall elevation in blood pressure, changes in the circadian amplitude and/or acrophase of blood pressure are taking place. Two new disease risk syndromes associated with large increases in vascular disease risk are circadian hyper-amplitude-tension (CHAT), a condition characterized by an excessive circadian amplitude of blood pressure, and chronome (time structure) alterations in heart rate variability. Increases in risk related to these disease risk syndromes are larger than any of the other risk factors tested by us so far on the same data sets, including old age and an elevation of blood pressure itself ('hypertension') $(15,16)$. The availability of noninvasive ambulatory monitors to measure automatically blood pressure, heart rate and R-R intervals around the clock for spans of one week or longer facilitates the collection of data for a refined diagnosis and also for a more rigorous assessment of responses to timed interventions. With the forthcoming technological advances, one hope in clinical chronobiology is a shift in emphasis toward the 'primary' prevention of disease and toward 'pre-habilitation'. By the earlier interventions prompted by the diagnosis of rhythm alterations within the physiological range, we may well decrease the need for 're-habilitation'. The number of strokes may well be reduced if single blood pressure measurements are replaced by time series allowing the diagnosis of CHAT and if timed interventions are instituted once the diagnosis has been made.

Luiz Menna-Barreto: Martin, you talk only of circadian rhythms, is that on purpose?

Martin Ralph: The reason for talking about circadian rhythms is that this is where the scientific community tends to have some degree of enlightenment. Talk about circannual rhythms and interest diminishes. I agree that there are those within the chronobiology field that would argue that ultradian rhythms are important. However, I would argue that circadian rhythms are going to remain the model for other aspects of rhythmicity. Personally, I use the cardiac cycle as a model for the circadian cycle, but this is theoretical.

Timothy Monk: Regarding ultradian and infradian rhythms I agree that they are important - I think, though, that in changing medical practice and public policy there is a real danger in overcomplicating the picture for those making the decisions. It is for that reason that $I$ favor a concentration on the circadian domain - at least until we have convincingly won that battle.

Germaine Cornélissen: I agree with the comment by Martin Ralph. Chronobiology is more than focus on the circadian system, as important as it may be. Work in our laboratory has gathered evidence for the endogenicity of other rhythmic components, such as the about weekly and the about yearly variations (17). The biological week is particularly prominent in relation to growth, regeneration and repair. Sharp peaks visible to the naked eye, recurring at intervals of 7 days, are apparent in the data on mitotic index and DNA synthesis during the regeneration of the kidney after unilateral nephrectomy or contralateral ischemia studied by Hübner (18). The unusually long series of self-measurements and data on morbidity/ mortality statistics available from different department of health statistics also indicate the presence of cycles with much longer periods, such as the about 10.5-year component resembling the solar activity cycle. For 
instance, an about 10.5-year periodicity is found for mortality from myocardial infarction in Minnesota, recorded between 1968 and 1996, accounting for a $5 \%$ increase in deaths during years of high versus years of low solar activity (16). We are also learning that organisms respond to nonphotic effects of the sun, such as magnetic disturbances, that decrease heart rate variability, a mechanism involved in the onset of myocardial infarctions (19). As we are venturing on longer and longer journeys into space, this may soon become a 'hot topic'. Physicists are already well aware of problems caused by such magnetic storms in communication satellites (20).

Israel Ashkenazi: I do agree that main outputs are circadian. But if we want to manipulate rhythms for practical purposes (medicine, cognitive, shift work, etc.) and we neglect the facts - 1) that it is possible that the real oscillators are ultradian; 2) that the circadian output is a compound one - we may loose an important track in the practical application of chronobiology.

Pablo Valdez: Although not so popular now in the field of chronobiology, if we are talking about future trends, ultradian and infradian rhythms may offer new phenomena and interesting questions.

Israel Ashkenazi: As to the circadian output - I am not opposed to its endogenous existence. In certain systems this may be obligatory (neurons) and in others it can be compound rhythms structured by ultradian components. I still think that we have to move in the unfashionable direction and pay more attention to ultradian components as they may be the main machinery of structuring rhythms. As to the question that Martin raised, human chronobiology must be first studied at the population level. There are too many components involved in shaping and phasing a rhythm and the information must be gathered from population studies.

Martin Ralph: Israel, agreed, human chronobiology must be studied at the popu- lation level; however, this may not lead to general acceptance. My comment was based on the principle that humans will consider something important if it has immediate consequences. Chrono-issues have the problem that they are important in the long term, but we can ignore them for short-term gain. So, any type of medical intervention that is based on this precept will take a back seat to an immediate cure. We can ignore short-term sleep deprivation if it will gain us an edge in business, for example, not considering the fact that we may impose the deprivation for years. What hope is there of finding an acceptable chronopharmaceutical, if the public can easily dismiss the warnings.

Luiz Menna-Barreto: We have shown that active and healthy elderly people do not necessarily show a disruption or even a dampening of their circadian rhythms (21). I understand Dr. Monk has something to say about that.

Timothy Monk: First with regard to the elderly, yes we have shown that in the very healthy elderly the endogenous circadian pacemaker can function very well indeed (as measured by us in rectal temperature rhythms and by Czeisler in melatonin rhythms). Importantly, though, the circadian message can get attenuated in its journey to the psychological rhythms of alertness and performance. In my view, this may be one pathway by which sleep is disrupted in the elderly.

\section{Chronodrugs}

Luiz Menna-Barreto: Chronodrugs are not exactly a big hit, or are they, or will they be?

Timothy Monk: I find it very interesting to believe that after all these years we do not have a real meaningful chronobiotic (i.e., a pharmacological zeitgeber). I wonder whether we ever will!

Luiz Menna-Barreto: Maybe we will have a meaningful drug when we come closer to understanding the timing system as a sys- 
tem and not as a sum of clocks.

Hugo Aréchiga: From the information available on neurotransmitters acting on CNS neurons, does any one care to speculate on the development of drugs capable of inducing helpful changes of phase in humans? For instance, phase-shifting effects have been documented for 5-HT and other transmitters, and the effects of melatonin may require updating.

Raul Aguilar-Roblero: The main problem with manipulating neurotransmitters is their involvement in other behavioral systems. How could we target such a drug at least mainly to the circadian system? Could triazolam or melatonin be good examples?

José Cipolla: I agree completely with Raul. The temporal organization of biological functions is the obstacle considering medical application of chronobiology.

Israel Ashkenazi: Tim, if you believe in one master clock then you would have a chance for a chronobiotic. I as a geneticist do not conceive the presence of one master clock but view a hierarchy or a network; thus I am not looking for a chronobiotic but rather for an assembly of natural signals.

Timothy Monk: Yes, I believe that may be the reason we have failed. My question to you would be: "can an assembly of compounds ever be put together which would act as a significant pharmacological zeitgeber?"

Israel Ashkenazi: What Tim stated is important - in our experience on model mouse systems we found that administration of the drugs phase shifts the rhythm of the target so we added a steroid that rephased this specific rhythm target - this may be of some help to chronomedicine.

Naoto Burioka: I believe that chronodrugs can be easily designed based on extensive existing chronobiological evidence. Pharmaceutical companies need them now. Drugs for the chronotherapy of asthma have already been developed in Japan and are used widely there. The transdermal 32 -agonist patch that was developed in Japan is especially useful for patients with asthma, whose symptoms frequently worsen around $4 \mathrm{am}$. Chronotherapy is clinically very useful for many other diseases as well. For instance, in the field of cancer, Franz Halberg $(22,23)$ showed that 2-year disease-free survival could be doubled when a relatively nonspecific marker, namely tumor temperature, was used to guide the radiotherapy of patients with large tumors of the oral cavity. Radiation was applied for five weeks. Patients were randomly assigned to receive daily treatment at one of five circadian stages, either at the time of their daily peak tumor temperature or 4 or $8 \mathrm{~h}$ before or after that time. Tumor regression rate was largest for those patients receiving the treatment at the time of their peak tumor temperature. Marker rhythms, such as tumor temperature in the above example, are very useful for the individualization of optimal treatment schedules. Potential marker rhythms are peak expiratory flow for asthma and blood pressure and heart rate in the field of cardiology. Optimization can be achieved not only in relation to circadian rhythms, but also in relation to other components. In the experimental laboratory, the merits of a combined circaseptan/circadian optimization have been demonstrated for lentinan (in relation to cancer) (24) and cyclosporine (an anti-rejection drug widely used after organ transplantation) (25). In addition to the transdermal patch for asthma developed in Japan, technological advances are likely to facilitate the development of other chronotherapeutic modalities. Drug administration devices that can be programmed to modulate the drug dose over time are a case in point. In this respect, the pacemakers, cardioverters and defibrillators already rely on built-in sensors to determine the need for treatment and may be ready soon to close the gap between physiological monitoring and treatment administration (26).

Regina Markus: My opinion is that an important issue is the administration of the 
drugs currently available at the proper chronobiological time. Therefore, the knowledge of the change in the time control during the development of the pathological process is also relevant.

Raul Aguilar-Roblero: I think that the idea of proper timing of drug delivery may in part solve the problem of proper targeting of the drugs. Do you think we may eventually be able to "sell" this concept to pharmaceutical companies or scientists as "intelligent drugs" in order to get their attention? I know it will be intelligent therapy.

Regina Markus: I think that we have two problems, one is the use of drug delivery at the proper time, and the other is the knowledge of the proper time of administration. Therefore the problem should be solved at two levels, medical and pharmacy schools on one hand and the industry on the other.

Germaine Cornélissen: I agree with the last comment by Raul Aguilar. "Intelligent therapy" will play an important role in allowing chronotherapy to enter the mainstream of medicine. Chemical advances aiming at more accurate targeting of drugs and the development of sensors for implantable devices are cases in point. We have come a long way since the first implantable pacemaker developed by Earl Bakken!

Alexandre Menezes: About a proper timing: we cannot forget the influence of the rhythms on the performance. Many clinical evaluations are made at a single moment. And if this evaluation is made at a time of low performance?

Hugo Aréchiga: Raul is touching on an interesting issue in the development of pharmaceutical applications of chronobiology. There are already some drugs presented in time-controlled devices. There is ample room here for future studies.

José Cipolla: The point is that the medical community is too much influenced by the pharmaceutical companies, which continue to ignore circadian organization because this would imply a complete change in the para- digm of analysis of human health with its consequences.

Hugo Aréchiga: I think it would be highly appropriate to have some discussion on potential phase-setting drugs, for instance, melatonin.

José Cipolla: I would like to hear the opinion of the colleagues on the postulated and putative role of melatonin in the regulation of the circadian rhythms: in the regulation of the clock and in the regulation of the expression of the circadian rhythms.

Timothy Monk: It is not clear to me that melatonin could ever be useful as a chronobiotic to any sighted people (although it seems to be quite useful for blind people without a retinohypothalamic tract). What I believe is that melatonin is useful as a way of allowing sleep at the "wrong" circadian phase (i.e., for the air traveler and night worker). If we can show that this is safe, this might be a great use for melatonin.

Israel Ashkenazi: With all due respect, the number of reports regarding unpleasant side effect is increasing - so what is the opinion of those who favor the use of melatonin? Should we suggest it freely as it is done now? In the US melatonin is available over the counter. In Israel it requires a certified prescription.

José Cipolla: I think that, given all the work on its physiological action, melatonin should be prescribed only under medical supervision (after our medical colleagues are properly informed about its actions).

Germaine Cornélissen: A lot of work is now being done on melatonin (26). This is another example of the fact that the circadian amplitude may be informative apart from the nocturnal concentrations or the 24-h average. We have seen that the circadian amplitude of melatonin is altered both in the presence of a higher risk of breast cancer and after the fait accompli of cancer (27). The changes are in opposite directions and in each case there was no difference in the 24-h average. Our work on melatonin has also 
suggested that daytime values may be informative in their own right, notably after logtransformation of the data to keep the distribution closer to normal (28). The late Professor Tarquini of Florence, Italy, and his colleagues Federico Perfetto and Roberto Tarquini have shown a circannual modulation of daytime concentrations of melatonin, but an about half-yearly modulation of the nocturnal values (29). A comparison with data collected closer to the pole where geomagnetic effects are stronger suggests that the 6-month component may reflect the effect of nonphotic (geomagnetic) solar effects on the pineal gland. The latter has been shown to be capable of acting as a receptor of low intensity magnetic fields.

Raul Aguilar-Roblero: Another important issue which has not been mentioned is the need to extend the view of regulation in the time domain of physiological processes. Although this concept is now accepted by biologists, it still is a novel concept for the medical community. Rhythms of any frequency are generally viewed as a phenomenon rather than as part of a mechanism involved in the regulation and integration of functions (30). I think it is necessary to push this concept among the lay public.

Martin Ralph: I agree with Raul. Regulation in the time domain is not particularly important for the medical community. It is acknowledged, it is accepted, then it is ignored. For the general public, it is interesting and sometimes exciting to hear about, but there is nothing that need be done about temporal hygiene. Cure something.

Israel Ashkenazi: Martin is right - until now there is no real evidence for chronoefficacy but only slight evidence for chronotoxicity of practical treatment. In this area chronobiology loses to targeted medications.

Germaine Cornélissen: I think it would be important to refer at this time to the considerable efforts by different laboratories to bring chronotherapy within the mainstream of medicine. An earlier comment by
Naoto Burioka indicated the availability of timed treatment for asthma. Also discussed separately by Naoto are the early successes of chronoradiotherapy of cancer achieved by Franz Halberg in India with B.D. Gupta. Considerable gains from chronochemotherapy of cancer have already been documented. Even if chronotherapy has not yet become an integral part of current medicine, these results should not be ignored.

Martin Ralph: Intelligent chronotherapy will only enter the mainstream if it can be shown to have unequivocal advantages. If not, it is a hindrance to the application of other medical interventions.

Timothy Monk: It may well be that chronopharmaceuticals become drugs of abuse. Many of us are concerned about the possibility that drugs such as Modafinil might become the "Viagra" of sleep and wakefulness.

Luiz Menna-Barreto: Please forgive my large text, but I would like to share our recent experience on what could be a successful application of chronobiology, not exactly a "cure", but... Adolescents show a phase delay of sleep onset which seems to be related to puberty. After that study we followed a group of students aged 10-11 years along a transition from an afternoon schedule to a morning schedule, a rather common transition in our country. Sleepiness increased, as well as an extension of sleep episodes during weekends, suggesting a sleep-deprivation effect of the transition (Mello L, Louzada F and Menna-Barreto L, unpublished results). Aware of these results, school authorities changed the schedule, allowing students to remain in the afternoon shift - sleepiness was less important and the weekend extension was reduced. This occurred in the last two years in a public school here on the university campus and we are now involved in a discussion whose goal is to discuss a possible reorganization of school schedules. As far as we know, in Israel and in the US there are similar efforts. 
Martin Ralph: I am aware that schedule changes can have profound effects on performance. The problem for chronobiology as I see it is that we are dealing with a problem that manifests itself in populations rather than in individuals. Everyone knows that cancer and heart disease can kill the individual, but sleep deprivation on the population scale causes what? More accidents perhaps, and a shorter life span, if my data are to be believed.

Raul Aguilar-Roblero: With respect to the effects of sleep deprivation, I think that here is an example of the relevance of temporal organization and the perception of well being. However, I found it difficult to discriminate between the chronobiological and the state-dependent aspects involved in sleep manipulations.

Timothy Monk: The problem with regard to populations is that sleep is the poor relative - only gets done when everything else on the list has been done. As chronobiologists we have two jobs with regard to this issue: 1) point out to people the error of their ways, and 2) try to develop compounds and strategies that might help folks anyway. It's a bit like asking cardiovascular patients to change their diet, but also working on cholesterol drugs for when they don't!

Pablo Valdez: It has been demonstrated repeatedly that shift work affects human circadian rhythms, but it seems that a morning shift has also some impact on circadian rhythms and the sleep-wake cycle. Is it better for human physiology to work in afternoon shifts?

Timothy Monk: Morning shifts that start very early truncate sleep (because of TV schedules, social events, etc.). Yes, evening shifts are the least disruptive biologically but are horrendous socially and domestically. The shift work problem is very multifaceted.

Luiz Menna-Barreto: Tim's statement on evening shifts reminds me of comments by parents of kindergarten children who say that early evening is the time to share family life and report the effort their kids make to keep awake for that contact.

\section{Methods}

Luiz Menna-Barreto: Much of what we shall call advancements in the future depends on new methods able to encompass the complexity of timing systems.

Germaine Cornélissen: One problem, in my opinion, is that many protocols tend to compare only two or at most three groups. From a purely statistical viewpoint, we have shown that chronobiological pilot designs are very powerful. They consist of assigning patients to at least six time points, e.g., along the circadian scale, at 4-h intervals or at 3-h intervals during waking. Compared to oneway ANOVA, the single cosinor has a higher power, primarily because the use of a model with an 'anticipated' period keeps the number of degrees of freedom low, whereas in an ANOVA, each additional group adds another degree of freedom to the model. If only two or three time points are selected for testing, they may not necessarily be placed in the most strategical manner. By covering the whole cycle, the circadian response rhythm can be assessed. In addition to a more precise and more accurate estimation of the average response, information also is available concerning the times of minimal and maximal response, and the extent of gain from administering treatment at the optimal time (31-34). There is one aspect of chronobiology that has not yet been covered. Nonlinear dynamic techniques are now being applied to assess chaotic or nonlinear properties. Methods of deterministic chaos have been used recently in fields such as cardiology and pulmonology as well as in neuroscience. Naoto has done some interesting studies in this direction.

Naoto Burioka: I used a new nonlinear method to analyze time series of respiratory movement during sleep. This method can plot all time series as an object (attractor) in 
the state-space (phase space) and detect the geometrical structure of the attractor $(35,36)$. Chaotic properties that have a fractal structure in the attractor have recently been observed in biological signals (e.g., ECG, EEG and respiratory movement). I analyzed the attractor from respiratory movement during sleep by using the correlation dimension (D2) computed according to the GrassbergerProcaccia algorithm (36) as well as by using the approximate entropy (ApEn) (37). Moreover, the use of surrogate data (38) revealed nonlinear features in the time series of respiratory movement during sleep. I found that respiratory movements follow a nonlinear deterministic process. The most impressive and statistically significant reduction of D2 or ApEn was observed during stage IV, that is deep sleep, while D2 or ApEn increased during REM sleep. The values of D2 and ApEn, which describe the complexity of biological systems, change rapidly according to sleep stage.

Luiz Menna-Barreto: It is time to finish our chat, now, incredible how fast time went by. It has been great having you all participate in this activity which I hope will prove to have been useful for all.

\section{Acknowledgments}

We wish to thank the Council of the $\mathrm{SBNeC}$ for its initiative in holding electronic symposia, particularly in the person of Dr. Cláudio Cunha who organizes the series. Leila Affini organized the bibliography and edition of the final version.

\section{References}

1. King DP \& Takahashi J S (2000). M olecular genetics of circadian rhythms in mammals. Annual Review of Neuroscience, 23: 713-742.

2. Aréchiga H (1993). Circadian rhythms. Current Opinion in Neurobiology, 3: 10051010.

3. Giebultowicz J M (2000). Molecular mechanism and cellular distribution of insect circadian clocks. Annual Review of Entomology, 45: 769-793.

4. Shearman LP, Sriram S, Weaver DR, Maywood ES, Chaves I, Zheng B, Kume $\mathrm{K}$, Lee CC, van der Horst GT, Hastings MH \& Reppert SM (2000). Interacting molecular loops in the mammalian circadian clock. Science, 288: 1013-1019.

5. Aréchiga H \& Rodríguez-Sosa L (1997). Coupling of environmental and endogenous factors in the control of rhythmic behavior in decapod crustaceans. J ournal of the Marine Biological Association of the United Kingdom, 77: 17-29.

6. Giebultowicz J M, Stanewsky R, Hall J C \& Hege DM (2000). Transplanted Drosophila excretory tubules maintain circadian clock cycling out of phase with the host. Current Biology, 27: 107-110.

7. Yamazaki S, Numano R, Abe M, Hida A Takahashi R, Ueda M, Block GD, Sakaki Y, Menaker M \& Tei H (2000). Resetting central and peripheral circadian oscillators in transgenic rats. Science, 288: 682-685.

8. Aréchiga H \& Rodríguez-Sosa L (1998). Circadian clock function in isolated eyestalk tissue of crayfish. Proceedings of the Royal Society of London. B, Biological Sciences, 265: 1819-1823.

9. Naylor E (1997). Crab clocks rewound. Chronobiology International, 14: 127-130.

10. Hastings M \& Maywood ES (2000). Circadian clocks in the mammalian brain. Bioessays, 22: 23-31.

11. Dunlap JC (1999). Molecular bases for circadian clocks. Cell, 96: 271-290.

12. García U \& Aréchiga H (1998). Regulation of crustacean neurosecretory cell activity. Cellular and Molecular Neurobiology, 18: 81-99.

13. Halberg F, Cornélissen $G$, Carandente $A$, Bakken E \& Young E (1993). Chronobiologic perspectives of international health care reform for the future of children. Chronobiologia, 20: 269-275.

14. Comélissen $G$, Delmore $P$, Bingham $C$, Rutledge G, Kumagai Y, Kuwajima I, Suzuki Y, Kuramoto K, Otsuka K, Scarpelli PT, Tarquini B, Cagnoni M, Garcia L, Zaslavskaya RM, Syutkina E, Carandente F, Rapoport SI, Romanov YA, Tamura K, Bakken E \& Halberg F (1993). A response to the health care crisis: a "health start" from "womb to tomb". Chronobiologia, 20: $277-291$.

15. Halberg F, Cornélissen G, Halberg J , Fink $\mathrm{H}$, Chen $\mathrm{C}-\mathrm{H}$, Otsuka $\mathrm{K}$, Watanabe $\mathrm{Y}$, Kumagai $Y$, Syutkina EV, Kawasaki T, Uezono K, Zhao ZY \& Schwartzkopff O (1998). Circadian hyper-amplitude-tension, CHAT: a disease risk syndrome of anti-aging medicine. J ournal of Anti-Aging Medicine, 1: 239-259.

16. Comélissen G, Halberg F, Schwartzkopff $O$, Delmore $P$, Katinas $G$, Hunter $D$, Tarquini B, Tarquini R, Perfetto F, Watanabe $Y$ \& Otsuka K (1999). Chronomes, time structures, for chronobioengineering for "a full life". Biomedical Instrumentation and Technology, 33: 152-187.

17. Cornélissen $G \&$ Halberg F (1994). Introduction to Chronobiology. Medtronic Chronobiology Seminar \#7 (Hard copy: Library of Congress (USA) Catalog Card \#94060580). [http://www.msi.umn.edu/ -halberg/introd/index.html].

18. Hübner K (1967). Kompensatorische Hypertrophie, Wachstum und Regeneration der Rattenniere. Ergebnisse der Allgemeinen Pathologie und Pathologischen Anatomie, 100: 1-80.

19. Comélissen $G$, Halberg $F$, Gheonjian $L$, Paatashvili $T$, Faraone $P$, Watanabe $Y$, Otsuka K, Sothem RB, Breus T, Baevsky 
R, Engebretson M \& Schröder W (2000). Schwabe's 10.5- and Hale's 21-year cycles in human pathology and physiology. In: Schröder W (Editor), Long- and ShortTerm Variability in Sun's History and Global Change. Science, Bremen, 79-88.

20. Rostoker G (1988). Nowcasting of space weather using the Canopus magnetometer array. Physics in Canada/La Physique au Canada, 44: 277-284.

21. Ceolim MF \& Menna-Barreto L (2000). Sleep/wake cycle and physical activity in healthy elderly people. Sleep Research Online, 3: 87-95.

22. Halberg $F$ (1977). Biological as well as physical parameters relate to radiology (Guest Lecture). Proceedings of the 30th Annual Congress on Radiology. PostGraduate Institute of Medical Education and Research, Chandigarh, India, 8.

23. Halberg F, Halberg J , Halberg E \& Halberg $F$ (1989). Chronobiology, radiobiology and steps toward the timing of cancer radiotherapy. In: Kaiser $\mathrm{H}$ (Editor, series), Goldson AL (Editor, volume), Cancer Growth and Progression. Kluwer Academic Publishers Group, Dordrecht, 9: 227-253.

24. Halberg E \& Halberg F (1980). Chronobiologic study design in everyday life, clinic and laboratory. Chronobiologia, 7: 95-120.

25. Liu T, Cavallini M, Halberg $F$, Comélissen G, Field J \& Sutherland DER (1986). More on the need for circadian, circaseptan and circannual optimization of cyclosporine therapy. Experientia, 42: 20-22.

26. Bartsch C, Bartsch $\mathrm{H}$, Blask DE, Cardinali $D$, Hrushesky W \& Mecke W (Editors) (2001). The Pineal Gland and Cancer: Neuroimmunoendocrine Mechanisms in Malignancy. Heidelberg Verlagsanstalt, Heidelberg (in press)

27. Tarquini $B$, Comélissen G, Tarquini $R$, Perfetto F \& Halberg F (1999). General and unspecific damping by malignancy of the circadian amplitude of circulating human melatonin? Neuroendocrinology Letters, 20: 25-28.

28. Cornélissen G, Halberg F, Burioka N, Perfetto F, Tarquini R \& Bakken EE (2000). Letter to the editor. [Re: Zeitzer J M, Daniels J E, Duffy J F et al. (1999). Do plasma melatonin concentrations decline with age? American J ournal of Medicine, 107: 432-436.] American J ournal of Medicine, 109: 343-345.

29. Tarquini B, Cornélissen G, Perfetto F, Tarquini R \& Halberg F (1997). Chronome assessment of circulating melatonin in humans. In vivo, 11: 473-484.

30. Aguilar-Roblero R, Escobar C, Torner C, Granados-Fuentes D, Salazar J \& Caldelas I (1997). Mecanismos generales de regulación fisiológica: acoplamiento de sistemas en oscilacion. In: Hiriart $M$, García-Sarzosa J , Mártínez E \& Velázquez $S$ (Editors), Actualización en Fisiología. SMCF-Universidad Nicolaita de San Nicolás de Hidalgo, Mexico, 241-254.
31. Günther R, Herold M, Halberg E \& Halberg F (1980). Circadian placebo and ACTH effects on urinary cortisol in arthritics. Peptides, 1: 387-390.

32. Comélissen G, Halberg F, Prikryl P, Dankova E, Siegelova J \& Dusek J (1991). International womb-to-tomb chronome study group: prophylactic aspirin treatment: the merits of timing. J ournal of the American Medical Association, 266: 31283129.

33. Bingham $C$, Cornélissen $G \&$ Halberg $F$ (1993). Power of "Phase 0" chronobiologic trials at different signal-to-noise ratios and sample sizes. Chronobiologia, 20: 179-190.

34. Halberg $F$, Bingham $C \&$ Cornélissen $G$ (1993). Clinical trials: the larger the better? Chronobiologia, 20: 193-212.

35. Takens F (1981). Detecting strange attractors in turbulence. In: Rand D \& Young BS (Editors), Lecture Notes in Mathematics. Springer Verlag, Berlin, 366-381.

36. Grassberger P \& Procaccia I (1983). Characterization of strange attractors. Physical Review Letters, 50: 346-349.

37. Pincus SM (1991). Approximate entropy as a measure of system complexity. Proceedings of the National Academy of Sciences, USA, 88: 2279-2301.

38. Theiler J , Eubank S, Longtin A, Galdrikian B \& Farmer J D (1992). Testing for nonlinearity in time series: the method of surrogate data. Physica D, 58: 77-94. 